BULLETIN Bulletin hispanique

HISPANIQUE Université Michel de Montaigne Bordeaux

123-1 | 2021

La forma de vida cortesana en la literatura de la Edad Media y el Siglo de Oro

\title{
Benito Jerónimo Feijoo, Obras completas, tomo VII.
}

\section{Poesía}

Oviedo, Instituto Feijoo de Estudios del Siglo XVIII/Universidad de Oviedo/Ayuntamiento de Oviedo, 2019

\section{Eduardo San José Vázquez}

\section{(2) OpenEdition}

\section{Journals}

Edición electrónica

URL: https://journals.openedition.org/bulletinhispanique/13225

DOI: 10.4000/bulletinhispanique. 13225

ISSN: $1775-3821$

\section{Editor}

Presses universitaires de Bordeaux

Edición impresa

Fecha de publicación: 20 junio 2021

Paginación: 397-401

ISBN: 979-10-300-0697-1

ISSN: 0007-4640

Referencia electrónica

Eduardo San José Vázquez, «Benito Jerónimo Feijoo, Obras completas, tomo vII. Poesía», Bulletin hispanique [En línea], 123-1 | 2021, Publicado el 20 junio 2021, consultado el 02 julio 2021. URL: http:// journals.openedition.org/bulletinhispanique/13225 ; DOl: https://doi.org/10.4000/bulletinhispanique. 13225

Este documento fue generado automáticamente el 2 julio 2021.

Tous droits réservés 


\title{
Benito Jerónimo Feijoo, Obras completas, tomo VII. Poesía
}

\author{
Oviedo, Instituto Feijoo de Estudios del Siglo XVIII/Universidad de \\ Oviedo/Ayuntamiento de Oviedo, 2019
}

\author{
Eduardo San José Vázquez
}

\section{REFERENCIA}

Benito Jerónimo Feijoo, Obras completas, tomo VII. Poesía (edición crítica, estudio introductorio y notas de Rodrigo Olay Valdés), Oviedo, Instituto Feijoo de Estudios del Siglo XVIII/Universidad de Oviedo/Ayuntamiento de Oviedo, 2019, 876 páginas.

1 La publicación de la Poesía de Benito Jerónimo Feijoo (1676-1764), en la ejemplar edición crítica de Rodrigo Olay Valdés, está llamada a ser una de las grandes novedades no solo literarias sino filológicas del hispanismo reciente: tanto por rescatar y ordenar un corpus textual que se suponía de menguado número y escaso valor -la obra poética de Feijoo- como por hacerlo con la mayor exigencia ecdótica. Una obra, ante todo, necesaria, pues salda la deuda editorial con uno de los autores importantes del siglo XVIII español, de quien no se sabía cuántos poemas había escrito, ni que lo que de él se conocía se había publicado con unas mínimas garantías filológicas; algo que dibujaba una situación editorial muy distinta a la de otros contemporáneos: Cadalso, García de la Huerta, los Moratín, Meléndez Valdés, Quintana, Cienfuegos o Jovellanos mismo.

2 Estamos, pues, ante una obra que permite descubrir a la vez a un poeta insospechado y a un joven estudioso que debuta como investigador de largo aliento con un trabajo que cualquier trayectoria cumplida aceptaría ostentar como jalón destacado. Mientras se escribe esta recensión el libro ha sido distinguido, de momento, con el premio anual de la Sociedad Española de Estudios del Siglo XVIII, ex aequo con la monografía de la acreditada dieciochista Mónica Bolufer Peruga Arte y artificio de la vida en común: los modelos de comportamiento y sus tensiones en el Siglo de las Luces (Marcial Pons Ediciones), lo que en realidad dobla el valor del galardón. 
El voluminoso saldo de la tarea hace el tomo vil de la serie de Obras completas de Feijoo, que, dentro de su Colección de Autores Españoles del Siglo XVIII, está llevando a cabo el Instituto Feijoo de la Universidad de Oviedo. La numeración de este tomo no obedece, sin embargo, al orden de los ya publicados, pues sale cuando únicamente han aparecido tres de la serie completa: el inicial de Bibliografía (1981) y los dos primeros de las Cartas eruditas y curiosas (2014 y 2018). Corresponde entonces a su lugar en el plan del magno proyecto editorial, que se completará con la edición crítica del Teatro crítico universal, la de la Correspondencia del autor y un tomo postrero de Varia.

4 En efecto, en 1981 José Miguel Caso González iniciaba la edición de las obras completas de Feijoo con la publicación del tomo I de Bibliografía, exhaustivo catálogo de las obras de y sobre el gran introductor y divulgador de la Ilustración española, que aún hoy, pendiente de una natural actualización, constituye una fuente inagotable y fiable de datos. La serie debía continuarse con la publicación, tomo a tomo, de la extensa producción del Padre Maestro, pero el proyecto se interrumpió para dar prioridad a las obras completas del otro gran ilustrado que cierra el Dieciocho español, Gaspar Melchor de Jovellanos, del que el profesor Caso González alcanzó a publicar en vida varios tomos. A punto de rematar sus continuadores en el Instituto Feijoo el encargo de ese proyecto, otra de sus antiguas colaboradoras, Inmaculada Urzainqui, asume hoy el anhelo de reemprender las obras completas de Feijoo, materializado hasta la fecha en la edición de los mencionados tomos de las Cartas eruditas, labor para la que coordina a un equipo de especialistas, responsables de fijar, modernizar y anotar el texto.

Bajo la misma dirección científica de Inmaculada Urzainqui, que se completa en esta ocasión con la de Elena de Lorenzo de Álvarez como directora de la tesis doctoral de la que nace este nuevo tomo de las Obras completas, Olay Valdés se decidió a acometer la edición de uno de los aspectos menos estudiados y peor valorados de la obra de Feijoo, su poesía. Poeta él mismo con nombre propio en las últimas promociones del siglo XX español, autor de los poemarios Cerrar los ojos para verte (2011, premio Asturias Joven), La víspera (2014, premio de la Crítica de Asturias), Saltar la hoguera (2019, premio Jaén) y Vieja escuela (2021, accésit del Adonáis), Rodrigo Olay ha conjugado dos facetas que no se estorban. Esto es especialmente notable en su labor investigadora, pues ante una empresa como esta cabía el riesgo del énfasis, cuando no de la hipérbole y del apresurado eureka. Señuelos que conjura con madurez esta edición, que si no podemos llamar definitiva es porque el azar añadirá tal vez otros hallazgos a la poesía de Feijoo, pero será difícil que alguien vuelva a acometer con este corpus literario una empresa de igual envergadura y resultados. Una obra poética que, de hecho, pasa a existir como tal, y no como piezas dispersas, a partir de la presente edición.

6 Es así que Feijoo solo había publicado tres poemas en vida, sin firmarlos con su nombre, cifra que iría aumentando hasta las ochenta composiciones identificadas de mano de investigadores posteriores. Los trabajos de Olay Valdés se emplazan, así, en el punto en que los dejaran, en la segunda mitad del siglo XX, María Elvira Muñiz, Isabel Visedo Orden o Dionisio Gamallo Fierros, quien dejó inconcluso su estudio Feijoo, mente lírica, de alguno de cuyos aportes inéditos logró beneficiarse esta edición. A partir de este punto de apoyo, la presente edición es capaz de esgrimir 131 composiciones poéticas de Feijoo, de las que, como matiza Olay Valdés, diez presentan problemas de atribución y trece son traducciones. Es decir, por la cuenta más corta su trabajo aporta al menos 28 nuevos poemas originales de Feijoo; hasta 51 poemas inéditos, en el cómputo más optimista. Como sea, es una cifra nunca alcanzada de un único impulso investigador; un 
aporte novedoso que en términos generales supone por sí solo entre el $20 \%$ y el $40 \%$ del corpus poético total de Feijoo.

7 Con esto, los resultados que arroja la labor de Olay Valdés pueden sintetizarse en cuatro puntos, de los que el editor se muestra consciente en su estudio introductorio: «esta edición descarta por completo y para siempre una serie de tópicos repetidos con insistencia: primero, que la poesía fuese una actividad marginal para Feijoo; segundo, que su escritura se concentrase ya en su mocedad, ya en su vejez; tercero, que Feijoo fuese en su tiempo un poeta totalmente desconocido; y cuarto, que la autoría de muchos de sus poemas siguiese sin poder confirmarse» (p. 11).

Pero la labor de esta edición no se agota en el aspecto cuantitativo de acopiar los poemas identificados, sino en su fijación textual, datación, ordenación y anotación. El editor acomete la fijación textual por cotejo de todos los testimonios conocidos de cada poema, impresos o manuscritos (ningún autógrafo feijoniano que haya pervivido, entre ellos), lo que, en su búsqueda, lo obligó a realizar estancias en más de una treintena de archivos y bibliotecas públicas y privadas. Tras el acopio, el cotejo y la construcción, donde sea posible, de un estema para cada pieza, con la intención de restituir el texto original del autor.

9 A continuación propone una ordenación del corpus, que es quizá el aspecto más comprometido de una edición de estas características. Una vez identificados como obra de Feijoo y tras proceder a la datación de los poemas, aplicando discrecionalmente criterios que van de lo filológico a lo contextual, el editor opta por ordenar el corpus según una limpia pauta racional -poemas publicados en vida, poemas publicados tras la muerte de Feijoo, poesía atribuida y poesía traducida, más un poema perdido de noticia indirecta hasta ahora-, secuenciada a su vez cronológicamente. A ella se subordina una división temática, si bien presente solo en la poesía de publicación póstuma, quizá por ser con mucho la más numerosa -poesía religiosa, fúnebre, encomiástica, amorosa y satírico-burlesca-. Sin duda algunas decisiones sobre estas últimas categorías serán cuestionables, pero el editor ha procedido en todo caso tratando de guiar sin despistar: ningún poema se perderá para el lector por causa de esta ordenación. Desde luego, la opción más aséptica, que hubiera sido una simple ordenación cronológica, no aportaría rendimiento semántico ni, en sí misma, sería orden alguno.

La mera exposición del aparato crítico que acompaña estas tareas aclara lo exhaustivo del trabajo. Por lo pronto, los índices finales, como mecanismo corrector del posible despiste de un poema a causa de los criterios de ordenación, tal como han sido expuestos arriba. Son, entre otros, tres fundamentales: un índice cronológico por orden de publicación, un índice métrico y otro de primeros versos. Entre todas las búsquedas cruzadas que posibilitan estas listas es raro que el lector pierda las coordenadas de un poema, de un verso o de una simple alusión en la lírica de Feijoo, pues a ellos se añade un prolijo índice onomástico final.

11 En el cuerpo de la obra, a cada poema precede un breve estudio, que orienta sin condicionar la lectura. Es la parte más personal y donde asoma el fino ojo crítico de Rodrigo Olay. No pocos de ellos podrían ser cabales artículos de investigación, como los que prologan al conocido romance «Desengaño y conversión de un pecador», los que anteceden a las cuatro composiciones (núms. 31-34) ofrecidas a la muerte de Luis I (1701-1724), o los que se dedican a esclarecer las identidades y circunstancias que se ocultan en sus poemas amorosos o en los satíricos. Secundan, por último, a cada composición poética un amplio sistema de notas a pie de página, la lista de testimonios 
de cada texto, el aparato crítico con todas las variantes y el diseño y explicación del estema de la pieza en particular.

Se trata, en suma, de toda una red de garantías y seguridades para que los lectores suspendan dudas sobre la fiabilidad del texto y se abandonen a descubrir la rica personalidad poética de Feijoo, especialmente, por novedosas en cantidad y calidad, sus quevedescas sales y salacidades satírico-burlescas o la pericia de sus ejercicios literarios en materia amorosa (como tales ejercicios de imitación o como encargos los defiende al menos Olay Valdés).

Es cierto que la buena crítica, aquella que no se cansó de recetar el Padre Maestro, precisa casi siempre de distancia. Una distancia crítica que aporta perspectiva y asegura la objetividad. Pero a veces la cercanía al objeto, el franqueo con el autor o haber sido asistido al empeño, dificultades y logros del trabajo, resultan más esclarecedores. Por esto, cualquiera de los investigadores del Instituto Feijoo de la Universidad de Oviedo que hemos estado cerca de la concepción y de la dilatada realización de este proyecto editorial puede aquilatar mejor, sin temor de parcialidad, su autoexigencia y las garantías del procedimiento.

Lo extraordinario del resultado se hace más notorio al exponer las cautelas y renuncias que aparejó el trabajo. Porque si algo ha conseguido esta edición de la poesía de Feijoo, además de sus hallazgos positivos, es resistir la tentación de anunciar el descubrimiento del poeta Benito Jerónimo Feijoo. Feijoo, razona Olay Valdés, hizo poesía, mucha más, con más constancia y de mayor calidad de lo que siempre se sostuvo; pero no fue poeta. o fue, como se deduce de las observaciones de su editor, también o además poeta. Esto es, además de lo que seguirá siendo siempre, el introductor y uno de los más brillantes exponentes del ensayo moderno en lengua española.

$15 \mathrm{Al}$ sopesar, en fin, un volumen como este, se hace presente su valor fundamental: pocas veces un estudio académico (mucho menos una ópera prima) habrá logrado superar tan netamente la tradición de la que partía, haciéndolo al mismo tiempo desde la más sincera deuda de gratitud hacia sus predecesores. Los comentarios de Olay Valdés destilan pasión investigadora y delectación filológica; veneración y franco deseo de pertenencia a una tradición que él, sin embargo, ha volteado y trastocado sensiblemente.

Tanto es así, que las asignaturas pendientes de esta edición no son más que los efectos deseables de su continuación: por un lado, la necesaria actualización del tomo I de Bibliografía de las Obras completas de Feijoo de la que se hablaba al comienzo de esta reseña: una puesta al día natural tras las cuatro décadas transcurridas desde el benemérito tomo de José Miguel Caso González y Silverio Cerra Suárez, e imperiosa tras el salto cuantitativo de esta edición de la Poesía de Feijoo.

17 Y, más aún, la necesidad de que esta edición crítica, que es sobre todo una herramienta para especialistas, genere sin esperar mucho una edición demótica. Un volumen al alcance de lectores curiosos, profesores y estudiantes, que sin reducir el corpus primario salga aligerada de aparato crítico para hacerla asequible al público general y dar plena carta de naturaleza al Feijoo, también, además, en buena hora, poeta. 


\section{AUTORES}

\section{EDUARDO SAN JOSÉ VÁZQUEZ}

Instituto Feijoo de Estudios del Siglo XVIII (Universidad de Oviedo) 